\title{
CO-TRANSLATIONAL PROTEIN AGGREGATION AFTER TRANSIENT CEREBRAL ISCHEMIA
}

\author{
C. L. LIU, P. GE, F. ZHANG, and B. R. HU* \\ Department of Neurology, University of Miami School of Medicine, PO Box 16960, Miami, FL \\ 33136, USA
}

\begin{abstract}
Transient cerebral ischemia leads to irreversible translational inhibition which has been considered as a hallmark of delayed neuronal death after ischemia. This study utilized a rat transient cerebral ischemia model to investigate whether irreversible translational inhibition is due to abnormal aggregation of translational complex, i.e. the ribosomes and their associated nascent polypeptides, initiation factors, translational chaperones and degradation enzymes after ischemia. Translational complex aggregation was studied by electron microscopy, as well as by biochemical analyses. A duration of 15 or 20 min of cerebral ischemia induced severe translational complex aggregation starting from $30 \mathrm{~min}$ of reperfusion and lasting until the onset of delayed neuronal death at $48 \mathrm{~h}$ of reperfusion. Under electron microscopy, most rosette-shaped polyribosomes were relatively evenly distributed in the cytoplasm of sham-operated control neurons. After ischemia, most ribosomes were clumped into large abnormal aggregates in neurons destined to die. Translational complex components consisting of small ribosomal subunit protein 6 , large subunit protein 28 , eukaryotic initiation factor-3 $\eta$, co-translational chaperone heat shock cognate protein 70 and cochaperone HSP40-Hdj1, as well as co-translational ubiquitin ligase c-terminus of hsp70interacting protein were all irreversibly clumped into large abnormal protein aggregates after ischemia. Translational components were also highly ubiquitinated. To our knowledge, irreversible aggregation of translational components has not been reported after brain ischemia. This study clearly indicates that ischemia damages co-translational chaperone and degradation machinery, resulting in irreversible destruction of protein synthesis machinery by protein aggregation after ischemia.
\end{abstract}

\section{Keywords}

brain ischemia; protein aggregation; co-translational folding; protein synthesis; ribosomal proteins; CHIP-; HSC70-; Hdj1-HSP40-; eIF-3ך

\begin{abstract}
Brain ischemia causes delayed neuronal death in some populations of neurons after transient cerebral ischemia and in penumbral neurons after focal ischemia (Ito et al., 1975; Kirino, 1982; Mies et al., 1991). During this days and weeks delayed period, neurons destined to die appear normal under the light microscope (Smith et al., 1984). Most cell surviving factors including cerebral blood flow, cellular ATP and ionic homeostasis are gradually recovered during the postischemic phase (Mies et al., 1991). However, in striking contrast, inhibition of protein biosynthesis persists only in neurons destined to undergo delayed neuronal death and has long been considered as a hallmark of delayed neuronal death after both transient
\end{abstract}


global and focal brain ischemia (Nowak et al., 1985; Magnusson and Wieloch, 1989; Mies et al., 1991; Hossmann, 1993; Hu et al., 2000, 2001; Kokubo et al., 2003).

Substantial progress has been made concerning the stress response in delayed neuronal death after ischemia (Sharp et al., 1999; Yenari et al., 2001; Giffard et al., 2004; Nishino and Nowak, 2004). In our previous electron microscopic (EM) studies, large quantities of aggregates labeled with ethanolic phosphotungstic acid (EPTA) were observed only in neurons destined to undergo delayed neuronal death after transient cerebral ischemia (Hu et al., 2000). Because EPTA preferentially reacts with proteins (Burry and Lasher, 1978), the aggregates stained with EPTA are likely composed of abnormal proteins. This conclusion is supported by the fact that postischemic neuronal aggregates contain ubiquitin immunoreactivity under immunoelectron and confocal microscopy (Hu et al., 2000). Unlike protein aggregation in genetic neurodegenerative diseases that arises from wrong DNA coding, ischemia-induced protein aggregation is probably due to disabilities of protein quality control systems after depletion of ATP during the postischemic phase (Hu et al., 2004).

What proteins are aggregated after transient ischemia? Newly synthesized proteins are the major sources of unfolded proteins in cells (Hartl and Hayer-Hartl, 2002). Translation of DNA genetic information into a linear polypeptide on a ribosome is normally done with fidelity (Frydman, 2001). However, to become functional proteins, most newly synthesized polypeptides have to overcome a rate-limiting hurdle, folding into a unique three dimensional conformation. Folding of most newly synthesized polypeptides during and after biosynthesis is not spontaneous, but must be assisted with molecular chaperones and chaperone-coupled degradation in a very crowded intracellular milieu. Otherwise, newly made polypeptides will aggregate and are highly toxic to cells (Hartl and Hayer-Hartl, 2002).

Despite the fact that neuronal ATP production and cerebral blood flow are recovered, inhibition of the overall rate of protein translation continues during reperfusion after global ischemia or in penumbral region after focal ischemia (Hossmann, 1993). Inhibition of translation is a transient incident in ischemia-surviving neurons, but is a persistent pathological event in neurons destined to undergo delayed neuronal death after both focal and global ischemia (Mies et al., 1991; Hossmann, 1993). Irreversible translational inhibition has long been considered as a hallmark of delayed neuronal death, i.e. neurons with persistent inhibition of protein biosynthesis will eventually die in a slow fashion (Nowak et al., 1985; Mies et al., 1991; Hossmann, 1993; Hu and Wieloch, 1993; Burda et al., 1994; DeGracia et al., 1996; Paschen, 2003). A brief eucaryotic initiation factor (eIF)-2alpha phosphorylation is responsible, at least in part, for the transient depression of translation in all ischemic neurons, but cannot account for irreversible translational inhibition in ischemia-vulnerable neurons (Burda et al., 1994; DeGracia et al., 1996). Molecular mechanisms underlying the irreversible inhibition of translation only in neurons destined to die after ischemia are unknown. This study demonstrated that ubiquitinconjugated protein (ubi-protein) aggregates and translational complex components are irreversibly clumped into large abnormal protein aggregates after brain ischemia. To our knowledge, irreversible protein aggregation of translational machinery has not been studied in any animal models of diseases including brain ischemia. This study suggests that irreversible inhibition of translation after ischemia is caused by irreversible aggregation of translational complex components. 


\section{EXPERIMENTAL PROCEDURES}

\section{Ischemia model}

Brain ischemia was produced using the two-vessel occlusion (2VO) model in rats (Smith et al., 1984). All experimental procedures were approved by the Animal Care and Use Committee at the University of Miami and were performed in compliance with the National Institutes of Health guidelines on the ethical use of animals. All measures were taken to reduce animal suffering and numbers of animals in this study. Male Wistar rats (250-300 g) were fasted overnight. Anesthesia was induced with $4 \%$ halothane and maintained with $1.5 \%$ halothane in an oxygen/nitrous oxide $(30 / 70 \%)$ gas mixture. Catheters were inserted into the external jugular vein, tail artery and tail vein to allow blood sampling, arterial blood pressure recording and drug infusion. Both common carotid arteries were encircled by loose ligatures. Fifteen minutes prior to ischemia induction and $15 \mathrm{~min}$ postischemia, blood gases were measured and adjusted to $\mathrm{PaO}_{2}>90 \mathrm{~mm} \mathrm{Hg}, \mathrm{PaCO}_{2} 35-45 \mathrm{~mm} \mathrm{Hg}$, and $\mathrm{pH} 7.35-7.45$ by adjusting the tidal volume of the respirator. Bipolar EEG was recorded before, during and after ischemia until recovery from the anesthesia. Brain ischemia was induced by withdrawing blood via the jugular catheter to produce a mean artery blood pressure (MABP) of $50 \mathrm{~mm} \mathrm{Hg}$, followed by clamping both carotid arteries for either 15 or $20 \mathrm{~min}$. MABP was maintained at $50 \mathrm{~mm} \mathrm{Hg}$ during the ischemic period by withdrawing or infusing blood through the jugular catheter. At the end of ischemia, the clamps were removed. Halothane was discontinued and all wounds were sutured. In all experiments, brain temperature was maintained at $37{ }^{\circ} \mathrm{C}$ before, during and after ischemia ( $15 \mathrm{~min}$ of reperfusion). Brains were collected at the ends of $30 \mathrm{~min}, 4,24$ and $72 \mathrm{~h}$ of reperfusion. Each experimental group consisted of at least four rats. For biochemical studies, brain tissues were obtained by freezing the brains in situ with liquid nitrogen. For confocal microscopy, rats were perfused with $4 \%$ paraformaldehyde in phosphate-buffered saline (PBS). For EM, rats were perfused with $2 \%$ paraformaldehyde and $2.5 \%$ glutaraldehyde in $0.1 \mathrm{M}$ cacodylate buffer.

\section{Histopathology}

Brain sections were cut at $30 \mu \mathrm{m}$ coronally with a vibratome at the dorsal hippocampal level and stained with Celestine Blue and Acid Fuschin. Neuronal histopathology was examined according to the method of Smith et al. (1984).

\section{EM}

Tissue sections from experimental and sham-operated control animals were stained either by $1 \%$ EPTA (purchased from Fisher Scientific, Fairlawn, NJ, USA) in combination with a ribosome-selective staining method, or by the conventional osmium- uranyl-lead method. Briefly, coronal brain sections were cut at a thickness of $120 \mu \mathrm{m}$ with a vibratome and postfixed for $1 \mathrm{~h}$ with $4 \%$ glutaraldehyde in $0.1 \mathrm{M}$ cacodylate buffer ( $\mathrm{pH}$ 7.4). For conventional osmium- uranyl-lead staining, sections were postfixed for $2 \mathrm{~h}$ in $1 \%$ osmium tetroxide in $0.1 \mathrm{M}$ cacodylate buffer, rinsed in distilled water and stained with $1 \%$ aqueous uranyl acetate overnight. The tissue sections were then dehydrated in an ascending series of ethanol to $100 \%$ followed by dry acetone and embedded in Durcupan ACM. Thin sections were counterstained with lead citrate prior to examination with a transmission electron microscope. For EPTA staining, sections were dehydrated in an ascending series of ethanol and stained for 40 min with 1\% PTA prepared by dissolving $0.1 \mathrm{~g}$ of PTA in $10 \mathrm{ml}$ of $100 \%$ ethanol and adding $200 \mu \mathrm{l}$ of $95 \%$ ethanol. Sections were then embedded in Durcupan ACM as a sandwich between two silicon-coated glass slides. Semithin and ultrathin sections were cut in a defined area such as CA1 region, and processed and examined by both light microscopy (LM) and EM. For post-embedding ribosome-selective staining, a chelationbased staining method termed "regressive" was used with modifications (Dvorak and Morgan, 2001). EPTA-stained sections were cut and mounted on uncoated copper 200-mesh 
grids before ribosomal selective staining. Ultrathin sections on grids were stained for $15 \mathrm{~min}$ in $5 \%$ aqueous uranyl acetate (UA) at $40{ }^{\circ} \mathrm{C}, 15 \mathrm{~min}$ in $0.2 \mathrm{M}$ aqueous EDTA disodium salt at room temperature, and $1 \mathrm{~min}$ in $3 \%$ lead citrate at room temperature. Ultrathin sections were examined with a Zeiss electron microscope.

\section{Subcellular fractionation}

Each tissue sample was prepared from a given rat. Four rats were used in each experimental group for statistical analysis. The dorsolateral neocortical tissue was homogenized with a Dounce homogenizer (35 strokes) in 10 vol. of ice-cold homogenization buffer containing $15 \mathrm{mM}$ Tris-base/HCl pH 7.6, $1 \mathrm{mM}$ DTT, $0.25 \mathrm{M}$ sucrose, $1 \mathrm{mM} \mathrm{MgCl}_{2}, 1 \mu \mathrm{g} / \mathrm{ml}$ pepstatin A, $5 \mu \mathrm{g} / \mathrm{ml}$ leupeptin, $2.5 \mu \mathrm{g} / \mathrm{ml}$ aproptonin, $0.5 \mathrm{mM}$ PMSF, $2.5 \mathrm{mM}$ EDTA, $1 \mathrm{mM}$ EGTA, $0.25 \mathrm{M} \mathrm{Na}_{3} \mathrm{VO}_{4}, 25 \mathrm{mM} \mathrm{NaF}$ and $2 \mathrm{mM}$ sodium pyrophosphate. The homogenate was centrifuged at $750 \times g, 4{ }^{\circ} \mathrm{C}$ for 10 min to obtain a crude nuclear fraction (P1) and supernatant (S1). The S1 supernatant was centrifuged at $10,000 \times g$ at $4{ }^{\circ} \mathrm{C}$ for $10 \mathrm{~min}$ to collect the pellet (P2). The S2 supernatant was further centrifuged at $165,000 \times g, 4{ }^{\circ} \mathrm{C}$ for $1 \mathrm{~h}$ to get a cytosolic fraction (S3) and a microsomal pellet (P3) that contained intracellular light membranes. The P2 was suspended with ice-cold homogenization buffer containing $1 \%$ Triton X-100 (TX100) and $400 \mathrm{mM} \mathrm{KCl}$, sonicated five times for $5 \mathrm{~s}$ each, washed on a shaker for $1 \mathrm{~h}$ at $4{ }^{\circ} \mathrm{C}$, and then centrifuged at $20,000 \times g, 4{ }^{\circ} \mathrm{C}$ for $10 \mathrm{~min}$ to obtain a TXinsoluble protein aggregate-containing fraction. Protein concentration in subcellular fractions was determined by the microbicinchonic acid (BCA) method of Pierer (Rockford, USA).

\section{Western blot analysis}

Western blot analysis was carried out with $12 \%$ sodium dodecyl sulfate-polyacrylamide gel electrophoresis (SDS-PAGE). Samples for Western blotting contained $10 \mu \mathrm{g}$ of protein in the TX-insoluble fraction, $50 \mu \mathrm{g}$ of protein in cytosol (S3) and $50 \mu \mathrm{g}$ of protein in P3. Four samples from four different rats were analyzed in every experimental group for statistical analysis. Following electrophoresis, proteins were transferred to an Immobilon-P membrane. The membranes were probed with the antibodies against ubiquitin (1:2000, Cell Signaling, Beverly, MA, USA), ribosomal small subunit 6 (S6) protein (1:2000, Cell Signaling), ribosomal large subunit protein 28 (L28) (1:700, Santa Cruz Biotech, Santa Cruz, CA, USA), heat-shock protein cognate form 70 (HSC70) (1:10,000, Stressgen, Victoria, Canada), Hdj1 heat shock protein 40 (HSP40) (1:1000, Stressgen), or c-terminus of hsp70interacting protein (CHIP) (1:1000, Calbiochem, San Diego, CA, USA). The membranes were then incubated with horseradish-peroxidase conjugated anti-mouse or anti-rabbit secondary antibody for $1 \mathrm{~h}$ at room temperature. The blots were developed with an ECL detection method (Amersham) and the optical densities of protein bands were quantified using Kodak 1D gel analysis software.

\section{Sedimentation analysis of translational complex}

The dorsolateral neocortical tissue $(100 \mathrm{mg})$ was homogenized with 10 vol. of ice-cold homogenization buffer. The homogenate was centrifuged at $20,000 \times g$ at $4{ }^{\circ} \mathrm{C}$ for $10 \mathrm{~min}$ to obtain a pellet and a supernatant fraction. The pellet containing the translational complex was suspended with 10 vol. of ice-cold homogenization buffer containing 1\% TX100 detergent and $400 \mathrm{mM} \mathrm{KCl}$ salt, sonicated five times for $5 \mathrm{~s}$, washed on a shaker overnight at $4{ }^{\circ} \mathrm{C}$, and then centrifuged at $20,000 \times g$ for $10 \mathrm{~min}$ to obtain a TX/salt-insoluble fraction that contain protein aggregates formed after brain ischemia (Hu et al., 2000, 2001). The detergent/salt-insoluble fractions were suspended in PBS with a sonicator and layered onto preformed 10-55\% linear sucrose gradients (made up in a buffer containing $20 \mathrm{mM}$ Tris$\mathrm{HCl} \mathrm{pH} 8,140 \mathrm{mM} \mathrm{KCl}, 5 \mathrm{mM} \mathrm{MgCl} 2,1 \mathrm{mM}$ dithiothreitol) in $13 \mathrm{ml} \mathrm{Beckman} \mathrm{SW41}$ centrifuge tubes. Centrifugation was performed at 35,000 r.p.m. for $3.5 \mathrm{~h}$ with a Beckman 
SW41Ti rotor. Gradient fractions were collected from the bottom of the centrifuge tube. Thirty-six fractions, each at a volume of $365 \mu \mathrm{l}$, were collected with a fraction collector. Absorbance at the ultraviolet (UV) wavelength of $260 \mathrm{~nm}$ in each fraction was measured with a Beckman spectrometer. Aliquots of $50 \mu \mathrm{l}$ of each fraction were analyzed by Western blotting. Western blots were labeled with antibodies against the following translational complex components, respectively: ribosomal small subunit proteins S6 (Cell Signaling), large subunit proteins L28 or eIF-3 $\eta$ (Santa Cruz Biotech), HSC70 and Hdj1 (HSP40) (Stressgen), and CHIP (Calbiochem). The blots were developed with an ECL detection method (Amersham Biosci, Piscataway, NJ, USA).

\section{Statistical analysis}

Immunoblots were analyzed with Kodak ID image analysis software. Each immunolabeled protein brand was calculated as the mean intensity value subtracted by the background value, and then presented as mean \pm S.D. ( $n=4)$ of a percentage of mean sham-operated control. One-way ANOVA followed by Fisher's PLSD post hoc test was employed to assess statistical significance $(P<0.05)$.

\section{RESULTS}

\section{Histopathology}

Brain sections were stained with Acid Fuchsin and Celestine Blue in $30 \mu \mathrm{m}$ vibratomesections. Neuronal damage was examined by light microscopy. Fifteen minutes of ischemia induced delayed neuronal death limited to dorsal CA1, dorsolateral striatum and less than $10 \%$ of neocortical neurons (data not shown, but see Hu et al., 2000), whereas 20 min of ischemia led to delayed neuronal death of almost all CA1 neurons, a few CA3 and dentate gyrus (DG) neurons, and about 50\% of dorsolateral neocortical neurons after $48 \mathrm{~h}$ of reperfusion (Fig. 1). Normal neurons are pyramid-like or round in shape (Fig. 1, arrowheads), whereas ischemic dead neurons have acidophilic cytoplasm, as well as dark, shrunken and polygonal nuclei (Fig. 1, arrows). All these results are consistent with previous studies (Smith et al., 1984).

\section{EM study of translational complex aggregation}

Conventional osmium- uranyl-lead electron micrographs of CA1 neurons from a shamoperated control rat and rats subjected to $15 \mathrm{~min}$ of ischemia followed by 4 and $24 \mathrm{~h}$ of reperfusion are shown in Fig. 2. Cytoplasmic rosette-shaped polyribosomes and ERassociated polyribosomal studs were normally scattered in the cytoplasm of sham-operated control CA1 neurons (Fig. 2, Sham, upper panel, arrows). The rough endoplasmic reticulum (ER), mitochondrion (M) and Golgi apparatus (G) were seen in the cytoplasm (Fig. 2, Sham, upper panel). After ischemia, rosette-shaped polyribosomes and the ER-associated polyribosomal studs were disaggregated into single ribosomes at $1 \mathrm{~h}$ of reperfusion (data not shown), consistent with many previous studies (Cooper et al., 1977; Nowak et al., 1985; Thilmann et al., 1986). However, these single ribosomes did not return into polyribosomal rosettes or the ER-associated polyribosomal studs, rather they formed large abnormal aggregates in the cytoplasm of CA1 neurons after 4 and $24 \mathrm{~h}$ of reperfusion (Fig. $2,4 \mathrm{~h}$ and $24 \mathrm{~h}$, upper panel, arrows). Higher magnification of the area indicated by arrows in Fig. 2 upper panel is further shown in Fig. 2 lower panel. Rosette-shaped polyribosomes were normally distributed in the cytoplasm of sham-operated control CA1 neurons (Fig. 2, Sham, lower panel, arrows). After ischemia, ribosomes were abnormally clumped into very large abnormal protein aggregates at 4 and $24 \mathrm{~h}$ of reperfusion (Fig. 2, $4 \mathrm{~h}$ and $24 \mathrm{~h}$, lower panel, arrows). 
Conventional osmium- uranyl-lead stains ribosomes as well as many other subcellular structures as illustrated in Fig. 2. To study ribosomal aggregation further, we stained brain sections with EPTA before embedding and then further stained with a ribosome-selective staining method after embedding (Fig. 3). Although membranes were not directly visible in EPTA-stained material due to lipid extraction in this staining protocol, the ER and M were often visible in negative contrast (Fig. 3, Sham, upper panel). Rats were subjected to either sham-surgery without ischemia or $15 \mathrm{~min}$ of ischemia followed by $24 \mathrm{~h}$ of reperfusion. The ER, M, nucleus $(\mathrm{N})$, and polyribosomal rosettes (arrowhead) were normally distributed in sham-operated control CA1 neurons (Fig. 3, Sham, upper panel). After ischemia, rosetteshaped polyribosomes were rarely seen, but large abnormal protein aggregates appeared in the cytoplasm (Fig. 3, 24 h, upper panel, arrows). Higher magnification showed that polyribosomes and ER-associated polyribosomal studs were normally distributed in shamoperated control CA1 neurons (Fig. 3, Sham, lower panel, arrows), But after ischemia, most ribosomes were clumped into large abnormal protein aggregates (Fig. 3, $4 \mathrm{~h}$, lower panel, arrows) and some single ribosomes were also observed in the cytoplasm of CA1 neurons (Fig. 3, $24 \mathrm{~h}$, lower panel, arrowheads). Large ribosomal aggregates were observed mainly in CA1 neurons after $15 \mathrm{~min}$ of ischemia, suggesting that ribosomal clumping into large aggregates was a pathological event after ischemia.

As mentioned, 15 min of ischemia induced delayed neuronal death limited to the CA1, striatum and less than $10 \%$ of neocortical neurons, whereas 20 min of ischemia expanded delayed neuronal death to some CA3 and DG neurons, as well as about 50\% of dorsolateral neocortical neurons after $48 \mathrm{~h}$ of reperfusion (see Fig. 1). After $20 \mathrm{~min}$ of ischemia, large abnormal ribosomal aggregates were also often found in neocortical (Fig. 4), CA3 and DG neurons (data not shown), consistent with the distribution of delayed neuronal death (see Fig. 1). Conventional electron micrographs of dorsolateral neocortical neurons from a shamoperated control rat and a rat subjected to $20 \mathrm{~min}$ of ischemia followed by $24 \mathrm{~h}$ of reperfusion are shown in Fig. 4. Cytoplasmic polyribosomes, $\mathrm{M}$ and $\mathrm{G}$ were normally scattered in the cytoplasm of sham-operated control neo-cortical neurons (Fig. 4, Sham Cx, arrows). After $20 \mathrm{~min}$ of transient cerebral ischemia, polyribosomes are clumped into large abnormal aggregates in some neocortical neurons after 4 (data not shown) and $24 \mathrm{~h}$ of reperfusion (Fig. 4, $24 \mathrm{~h} \mathrm{Cx}$, arrows). Higher magnification of the area indicated by arrows in Fig. 4 upper panel is further shown in Fig. 4 lower panel. Polyribosomes were normally distributed in sham-operated neocortical neurons (Fig. 4, Sham Cx, lower panel, arrows), but clumped into large abnormal aggregates in neurons subjected to $20 \mathrm{~min}$ of ischemia followed by $24 \mathrm{~h}$ of reperfusion (Fig. 4, $24 \mathrm{~h} \mathrm{Cx}$, lower panel, arrows).

\section{Biochemical analysis of translational complex aggregation}

EM results indicated that ribosomes were clumped into large abnormal protein aggregates in neurons destined to die after ischemia. When proteins become aggregated, their detergent/ salt solubility decreases dramatically (Kabakov and Gabai, 1994; Kazantsev et al., 1999; Hazeki et al., 2000; Stockel and Hartl, 2001). Because large quantities of tissues were needed to isolate the detergent/salt-insoluble protein aggregate-containing fraction, we utilized dorsolateral neo-cortical tissues from sham-operated control rats and rats subjected to $20 \mathrm{~min}$ of cerebral ischemia followed by $30 \mathrm{~min}, 4$ and $24 \mathrm{~h}$ of reperfusion for the following biochemical analysis of translational complex aggregation. Translational complex component S6 is a 40S ribosomal protein, L28 is a 60S ribosomal protein, HSC70 and Hdj1 are the major co-translational chaperones, and CHIP is a major translation-coupled ubiquitin ligase. CHIP, HSC70, Hdj1, S6 and L28 were all highly increased in the detergent/saltinsoluble protein aggregate-containing fraction after ischemia (Fig. 5, left panels). Deposition of CHIP, HSC70, Hdj1, S6 and L28 into the detergent-insoluble fraction started as early as $30 \mathrm{~min}$ of reperfusion, and continued at 4 and $24 \mathrm{~h}$ of reperfusion (Fig. 5, left 
panels). Concomitantly, translational complex components in the cytosolic $\mathrm{S} 3$ fractions were decreased for CHIP, HSC70 and Hdj1, and in the microsomal P3 fractions for S6 and L28 ribosomal proteins during the postischemic phase (Fig. 5, right panels).

To study translational complex aggregation further, we carried out sedimentation analysis of translational complex components in sucrose density gradients, in conjunction with immunoblotting. Equal amounts of neuronal tissues $(100 \mathrm{mg})$ from rats subjected to either sham surgery or $20 \mathrm{~min}$ of ischemia followed by $24 \mathrm{~h}$ of reperfusion were used in this sedimentation analysis of translational complex aggregation. The detergent/salt-insoluble fractions were resolved on performed $10-55 \%$ sucrose gradients by centrifugation, and the sedimentation profiles at the UV absorbance 260 (UV-260) were recorded (Fig. 6, top panel). Thirty-six fractions were collected from the gradients. The major sedimentation peak in non-ischemic sham-control samples was located at fractions 11-14, corresponding to the detergent/salt-washed ribosomal peak in the gradient, whereas the major sedimentation peaks of postischemic samples were shifted to much higher densities located at fractions 18 21 (Fig. 6). All 36 fractions collected from sucrose density gradients of control and postischemic samples were subjected to SDS-PAGE and analyzed by Western blot with antibodies against ubi-proteins, CHIP, HSC70, Hdj1, S6, L28, or eIF-3 $\eta$ (Fig. 6, lower immunoblot panels). eIF-3 $\eta$ is the eukaryotic protein synthesis initiation factor $3 \eta$. The high molecular weights of ubi-proteins, as well as CHIP, HSC70, Hdj1, S6, L28, and eIF-3 $\eta$ were resolved within the ribosomal peak in sham-operated control samples (Fig. 6, Sham, 14 immunoblot panels). However, relative to those in control samples, much larger quantities of all these translational complex components were shifted to higher sucrose densities in postischemic samples (Fig. 6, 24 h, 14 immunoblot panels).

\section{DISCUSSION}

Forebrain neurons after global ischemia and penumbral neurons after focal ischemia do not die immediately, but die several days and weeks after ischemia. During this maturation period, the light microscopic morphology of neurons destined to die is virtually normal. Most cell surviving factors including cerebral blood flow, cellular ATP and ionic homeostasis are gradually recovered. In striking contrast, protein synthesis is irreversibly inhibited only in neurons destined to die. Irreversible inhibition of translation has long been considered as a hallmark of delayed neuronal death after both focal ischemia and global ischemia, but the underlying mechanism is unknown (Cooper et al., 1977; Nowak et al., 1985; Thilmann et al., 1986; Mies et al., 1991; Hossmann et al., 1993; Hu and Wieloch, 1993; Burda et al., 1994; DeGracia et al., 1996). This study demonstrated that irreversible inhibition of protein synthesis is most probably caused by destruction of translational machinery via protein aggregation after ischemia. Both conventional and the EPTAselective EM staining methods show that ribosomes are clumped into large abnormal protein aggregates mainly in neurons destined to undergo neuronal death after brain ischemia. Translational complex components consisting of ribosomal small subunit protein S6, large subunit protein L28, co-translational chaperones HSC70 and Hdj1, translational initiation factor eIF-3 $\eta$, and co-translational ubiquitin ligase CHIP are all highly deposited into a detergent/salt-insoluble fraction that contains protein aggregates after ischemia. Sedimentation analysis further confirms that detergent/salt-insoluble translational complex components are aggregated into higher densities in a sucrose density gradient. Translational complex components are also highly ubiquitinated. Aggregation of ubi-quitinated proteins is an irreversible process (Angelidis et al., 1999; Ohtsuka and Hata, 2000). These results strongly suggest that translational complex components are clumped into large abnormal protein aggregates, resulting in irreparable damage to protein synthesis machinery after brain ischemia. In addition, translational complex aggregates are also associated with other 
subcellular organelles such as the ER and mitochoindria, and thus may damage these vital organelles after brain ischemia.

Newly synthesized proteins are the major sources of unfolded proteins in normal cells (Hartl and Hayer-Hartl, 2002). Folding of newly synthesized polypeptide occurs mostly at the levels of protein domain or multi-domains: folding cannot take place until an entire protein domain has emerged from the ribosome, i.e. co-translational folding (Frydman, 2001). Because ribosomes are highly abundant in cells, numerous nascent polypeptides normally emerge from their parent ribosomes at any given moment. Partially or newly synthesized polypeptide chains expose hydrophobic segments and are highly prone to intra-molecular misfolding and inter-molecular aggregation driven by the exposed hydrophobic force (Hartl and Hayer-Hartl, 2002). Therefore, co-translational folding generally requires: (1) the assistant chaperone protein HSC70; (2) its co-chaperone Hdj1; and (3) a cellular ATP supply. Any errors either owing to wrong genetic coding such as in genetic neurodegenerative diseases or malfunction of protein folding and degradation machinery such as after ischemia can cause protein misfolding and translational complex aggregation.

The best known chaperones for co-translational folding are the constitutive HSC70 and Hdj1 (Li et al., 1995). HSC70 contains an ATPase domain and a peptide binding domain, and carries out cycles of binding and release of nascent polypeptides during co-translational folding in an ATP-dependent manner. However, the kinetics of the HSC70-coupled substrate binding and release cycles is insufficient to compete with nascent chain aggregation during protein biosynthesis in normal cells, and thus must be accelerated by its co-chaperone Hdj1 which is a member of J-domain-containing HSP40 family. Hdj1 promotes HSC70 hydrolysis of ATP through its J-domains (Hartl and Hayer-Hartl, 2002). During this process, Hdj1 first binds to a nascent chain, and then the Hdj1-peptide substrate complex associates with HSC70 and ATP to transfer the nascent chain to HSC70 by hydrolysis of ATP. This cooperative interaction among Hdj1, HSC70 and ATP hydrolysis shifts HSC70 to its low affinity mode and allows release of bound polypeptide from HSC70. Co-translational folding of nascent peptides usually requires many cycles of HSC70mediated ATP binding and hydrolysis (Ohtsuka and Hata, 2000; Frydman, 2001; Hartl and Hayer-Hartl, 2002). If nascent chains cannot be folded successfully, they must be degraded by the ubiquitin-proteasomal system via recruitment of the ubiquitin ligase such as CHIP for degradation. CHIP binds to the HSC70-substrate complex through its N-terminus tetratricopeptide repeat (TPR) domain and conjugates HSC70 substrate with ubiquitin by its C-terminus U-box ubiquitin ligase activity (Murata et al., 2003).

Biochemical analyses of translational complex components in this study indicate that HSC70, Hdj1, eIF-3 $\eta$, CHIP, S6 and L28 are markedly deposited into detergent/saltinsoluble protein aggregate-containing fractions after brain ischemia. Sedimentation analysis further suggests that the translational complexes are abnormally shifted to higher sucrose densities and are highly ubiquitinated. Hdj1 is the first chaperone to encounter unfolded nascent polypeptides during translation, which may be the reason for its virtually complete deposition into protein aggregates after ischemia. Aggregated chaperones lose their activities permanently (Angelidis et al., 1999). It appears likely that nascent polypeptides on ribosomes cannot fold or degrade due to the disabilities of chaperone and degradation machinery after ATP depletion following ischemia. Consequently, unprocessed nascent polypeptides and their associated folding- and degradation-assistant chaperones and cochaperones are stacked (Angelidis et al., 1999; Ohtsuka and Hata, 2000; Frydman, 2001; Hartl and Hayer-Hartl, 2002), and gradually aggregated during the post-ischemic phase. Protein aggregation after brain ischemia is virtually an irreversible process (Hu et al., 2000, 2001). To our knowledge, co-translational complex aggregation has not been studied in animal models of diseases. Unlike protein aggregation in genetic neurodegenerative diseases 
that arises from wrong DNA coding, this study suggests that, ischemia-induced protein aggregation is due to disabilities of protein quality control systems after depletion of ATP, resulting in irreversible aggregation and destruction of protein synthesis machinery after brain ischemia. Irreversible aggregation of protein synthesis machinery can well explain the irreversible inhibition of protein synthesis that has long been considered as a hallmark of delayed neuronal death in vulnerable neurons after ischemia (Cooper et al., 1977; Mies et al., 1991; Hossmann et al., 1993; Hu and Wieloch, 1993; Burda et al., 1994; De-Gracia et al., 1996).

The present study has demonstrated that translational components appear to be major components of protein aggregates. In addition to translational components, whether other immature proteins or denatured mature proteins are also aggregated after brain ischemia remains to be studied (Liu and $\mathrm{Hu}, 2004$; Liu et al., 2004a). Several lines of evidence indicate that protein aggregation may play a causative role in delayed neuronal death after brain ischemia. Protein aggregation takes place immediately after ischemia and last for several days until delayed neuronal death occurs after transient cerebral ischemia (Hu et al., 2000). Measures that increase the capacity of protein quality control systems, such as overexpression of molecular chaperones and folding enzymes, reduce ischemic neuronal death. There is also strong evidence that unfolded proteins without chaperone protection are highly toxic to all types of cells and microorganisms, but different types of cells have varied susceptibilities to toxic unfolded proteins (Bukau et al., 1996; Hu et al., 2004; Giffard et al., 2004). Unfolded proteins are particularly detrimental to post-mitotic neurons because they can exert their deleterious effects for a long period. Then, why are some groups of cells, such as CA1 pyramidal neurons more vulnerable to the proteotoxicity than other populations of cells, as for instance DG granule cells after brain ischemia? In previous studies, we found that unfolded ubi-proteins are generated in both ischemically vulnerable and resistant neurons after ischemia (Hu et al., 2000, 2001). However, visible protein aggregates are seen mostly in ischemically vulnerable neurons, suggesting that unfolded ubi-proteins may have to accumulate to a certain degree to form EM-visible aggregates. Therefore, EM-visible protein aggregates may reflect a severe form of accumulation of toxic unfolded proteins after ischemia (Hu et al., 2004). The presence of quantitative differences in unfolded proteins between ischemic dying and surviving neurons leads us to a hypothesis that there is a common induction of toxic unfolded proteins in all ischemic brain regions. Differences in protein aggregation exhibited among different brain regions reflect a quantitative imbalance between the amounts of toxic unfolded proteins and the capacity of protein quality control systems to counter them. Therefore, the same constellation of co-translational complex aggregation seen in ischemic CA1 pyramidal neurons should also be found in ischemically resistant areas when the duration of ischemia is increased, resulting in damage to the protein quality control systems. This hypothesis is supported by the results from this study showing that co-translational complex aggregation is expanded to the neocortical neurons when the cerebral ischemic duration increased from $15 \mathrm{~min}$ to $20 \mathrm{~min}$ of ischemia.

\section{CONCLUSION}

This study indicates that ischemia damages co-translational chaperone and degradation machinery, resulting in irreparable damage to protein synthesis machinery via protein aggregation after ischemia.

\section{Acknowledgments}

This work was supported by National Institutes of Health grants NS040407 and NS36810. The authors thank Dr. Brand Watson for proof reading of this manuscript. Origin of work: Department of Neurology, University of Miami School of Medicine, Miami, FL 33136, USA. 


\section{Abbreviations}

CHIP

DG

eIF

EM

EPTA

ER

G

HSC

HSP

L28

M

MABP

$\mathbf{N}$

PBS

S6

SDS-PAGE

TX100

ubi-proteins

UV c-terminus of hsp70-interacting protein

dentate gyrus

eucaryotic initiation factor

electron microscopic

ethanolic phosphotungstic acid

endoplasmic reticulum

Golgi apparatus

heat shock cognate protein

heat shock protein

large ribosomal subunit protein 28

mitochondrion

mean artery blood pressure

nucleus

phosphate-buffered saline

small ribosomal subunit protein 6

sodium dodecyl sulfate-polyacrylamide gel electrophoresis

Triton X-100

ubiquitin-conjugated proteins

ultraviolet

\section{References}

Angelidis CE, Lazaridis I, Pagoulatos GN. Aggregation of hsp70 and hsc70 in vivo is distinct and temperature-dependent and their chaperone function is directly related to non-aggregated forms. Eur J Biochem. 1999; 259:505-512. [PubMed: 9914533]

Bukau B, Hesterkamp T, Luirink J. Growing up in a dangerous environment: a network of multiple targeting and folding pathways for nascent polypeptides in the cytosol. Trends Cell Biol. 1996; 6:480-486. [PubMed: 15157507]

Burda J, Martin ME, Garcia A, Alcazar A, Fando JL, Salinas M. Phosphorylation of the alpha subunit of initiation factor 2 correlates with the inhibition of translation following transient cerebral ischaemia in the rat. Biochem J. 1994; 302:335-338. [PubMed: 8092984]

Burry RW, Lasher RS. A quantitative electron microscopic study of synapse formation in dispersed cell cultures of rat cerebellum stained either by Os-UL or by EPTA. Brain Res. 1978; 147:1-15. [PubMed: 77699]

Cooper HK, Zalewska T, Kawakami S, Hossmann KA, Kleihues P. Delayed inhibition of protein synthesis during recirculation after compression ischemia of the rat brain. Acta Neurol Scand Suppl. 1977; 64:130-131. [PubMed: 268758]

DeGracia DJ, Neumar RW, White BC, Krause GS. Global brain ischemia and reperfusion: modifications in eukaryotic initiation factors associated with inhibition of translation initiation. J Neurochem. 1996; 67:2005-2012. [PubMed: 8863507]

Dvorak AM, Morgan ES. Ribosomes and secretory granules in human mast cells: close associations demonstrated by staining with a chelating agent. Immunol Rev. 2001; 179:94-101. [PubMed: 11292032] 
Frydman J. Folding of newly translated proteins in vivo: the role of molecular chaperones. Annu Rev Biochem. 2001; 70:603-647. [PubMed: 11395418]

Giffard RG, Xu L, Zhao H, Carrico W, Ouyang Y, Qiao Y, Sapolsky R, Steinberg G, Hu B, Yenari MA. Chaperones, protein aggregation, and brain protection from hypoxic/ischemic injury. J Exp Biol. 2004; 207:3213-3220. [PubMed: 15299042]

Hartl FU, Hayer-Hartl M. Molecular chaperones in the cytosol: from nascent chain to folded protein. Science. 2002; 295:1852-1858. [PubMed: 11884745]

Hazeki N, Tukamoto T, Goto J, Kanazawa I. Formic acid dissolves aggregates of an N-terminal huntingtin fragment containing an expanded polyglutamine tract: applying to quantification of protein components of the aggregates. Biochem Biophys Res Commun. 2000; 277:386-393. [PubMed: 11032734]

Hossmann K-A. Disturbances of cerebral protein synthesis and ischemic cell death. Prog Brain Res. 1993; 96:167-177.

$\mathrm{Hu}$ BR, Wieloch T. Stress-induced inhibition of protein synthesis initiation: Modulation of initiation factor 2 and guanine nucleotide exchange factor activity following transient cerebral ischemia in the rat. J Neurosci. 1993; 13:1830-1838. [PubMed: 8478677]

Hu BR, Janelidze S, Ginsberg MD, Busto R, Perez-Pinzon M, Sick TJ, Siesjo BK, Liu CL. Protein aggregation after focal brain ischemia and reperfusion. J Cereb Blood Flow Metab. 2001; 21 :865875. [PubMed: 11435799]

Hu, BR.; Martone, ME.; Liu, CL. Protein aggregation, unfolded protein response and delayed neuronal death after brain ischemia. In: Buchan, A.; Ito, U., editors. Maturation phenomenon in cerebral ischemia V. 2004. p. 225237

Hu BR, Martone ME, Jones YZ, Liu CL. Protein aggregation after transient cerebral ischemia. J Neurosci. 2000; 20(9):3191-3199. [PubMed: 10777783]

Ito U, Spatz M, Walker JT Jr, Klatzo I. Experimental cerebral ischemia in mongolian gerbils. I. Light microscopic observations. Acta Neuropathol (Berl). 1975; 32:209-223. [PubMed: 1180003]

Kabakov AE, Gabai VL. Stress-induced insolubilization of certain proteins in ascites tumor cells. Arch Biochem Biophys. 1994; 309:247-253. [PubMed: 8135534]

Kazantsev A, Preisinger E, Dranovsky A, Goldgaber D, Housman D. Insoluble detergent-resistant aggregates form between pathological and nonpathological lengths of polyglutamine in mammalian cells. Proc Natl Acad Sci U S A. 1999; 96:11404-11409. [PubMed: 10500189]

Kirino T. Delayed neuronal death in the gerbil hippocampus following ischemia. Brain Res. 1982; 239:57-69. [PubMed: 7093691]

Kokubo Y, Liu J, Rajdev S, Kayama T, Sharp FR, Weinstein PR. Differential cerebral protein synthesis and heat shock protein 70 expression in the core and penumbra of rat brain after transient focal ischemia. Neurosurgery. 2003; 53:186-190. [PubMed: 12823888]

Li GC, Mivechi NF, Weitzel G. Heat shock proteins, thermotolerance, and their relevance to clinical hyperthermia. Int J Hyperthermia. 1995; 11:459-488. [PubMed: 7594802]

Liu CL, Hu BR. Alterations of N-ethylmaleimide-sensitive ATPase following transient cerebral ischemia. Neuroscience. 2004; 128:767-774. [PubMed: 15464284]

Liu CL, Martone ME, Hu BR. Protein ubiquitination in postsynaptic densities after transient cerebral ischemia. J Cereb Blood Flow Metab. 2004a; 24:1219-1225. [PubMed: 15545915]

Magnusson K, Wieloch T. Impairment of protein ubiquitination may cause delayed neuronal death. Neurosci Lett. 1989; 96:264-270. [PubMed: 2541380]

Mies G, Ishimaru S, Xie Y, Seo K, Hossmann KA. Ischemic thresholds of cerebral protein synthesis and energy state following middle cerebral artery occlusion in rat. J Cereb Blood Flow Metab. 1991; 11:753-761. [PubMed: 1874807]

Murata S, Chiba T, Tanaka K. CHIP: a quality-control E3 ligase collaborating with molecular chaperones. Int J Biochem Cell Biol. 2003; 35:572-578. [PubMed: 12672450]

Nishino K, Nowak TS Jr. Time course and cellular distribution of hsp27 and hsp72 stress protein expression in a quantitative gerbil model of ischemic injury and tolerance: thresholds for hsp72 induction and hilar lesioning in the context of ischemic preconditioning. J Cereb Blood Flow Metab. 2004; 24:167-178. [PubMed: 14747743] 
Nowak TS Jr, Fried RL, Lust WD, Passonneau JV. Changes in brain energy metabolism and protein synthesis following transient bilateral ischemia in the gerbil. J Neurochem. 1985; 44:487-494. [PubMed: 3965620]

Ohtsuka K, Hata M. Molecular chaperone function of mammalian Hsp70 and Hsp40. Int J Hyperthermia. 2000; 16:231-245. [PubMed: 10830586]

Paschen W. Shutdown of translation: lethal or protective? Unfolded protein response versus apoptosis. J Cereb Blood Flow Metab. 2003; 23:773-779. [PubMed: 12843781]

Sharp FR, Massa SM, Swanson RA. Heat-shock protein protection. Trends Neurosci. 1999; 22:97-99. [PubMed: 10199631]

Smith ML, Auer RN, Siesjo BK. The density and distribution of ischemic brain injury in the rat following 2-10 min of forebrain ischemia. Acta Neuropathol (Berl). 1984; 64:319-332. [PubMed: 6507048]

Stockel J, Hartl FU. Chaperonin-mediated de novo generation of prion protein aggregates. J Mol Biol. 2001; 313:861-872. [PubMed: 11697909]

Thilmann R, Xie Y, Kleihues P, Kiessling M. Persistent inhibition of protein synthesis precedes delayed neuronal death in postischemic gerbil hippocampus. Acta Neuropathol (Berl). 1986; 71:88-93. [PubMed: 3776478]

Yenari MA, Dumas TC, Sapolsky RM, Steinberg GK. Gene therapy for treatment of cerebral ischemia using defective herpes simplex viral vectors. Ann N Y Acad Sci. 2001; 939:340-357. [PubMed: 11462790] 


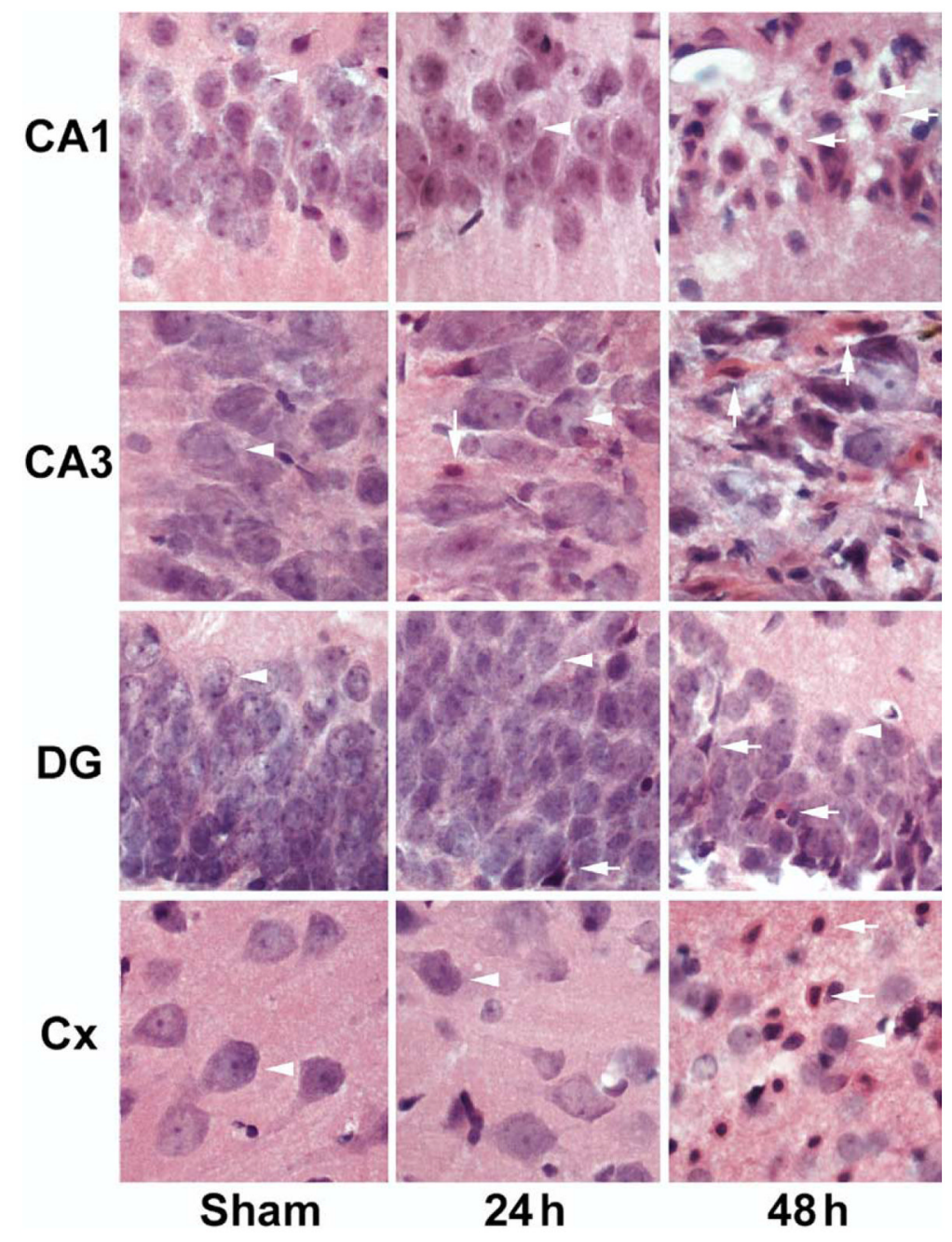

Fig. 1.

Histopathology of hippocampal CA1, CA3, DG, and neocortical neurons stained with Acid Fuchsin and Celestine Blue after ischemia. Brain sections were obtained from shamoperated control rats and rats subjected to $20 \mathrm{~min}$ of cerebral ischemia followed by 24 and $48 \mathrm{~h}$ of reperfusion. No neuronal death was found in brain sections from the sham-operated control. A few dead neurons were seen at $24 \mathrm{~h}$ of reperfusion, whereas all CA1 neurons, a portion of CA3 and DG neurons and about $50 \%$ neocortical neurons were dead after 20 min of cerebral ischemia. 

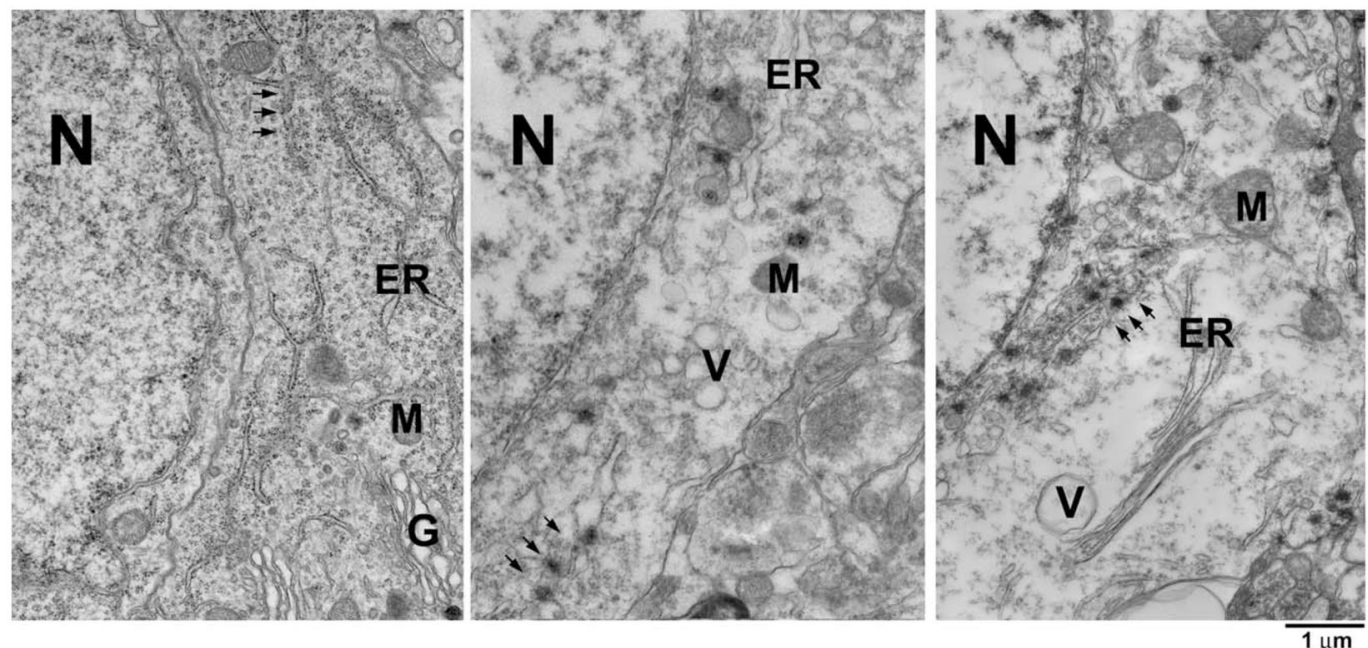

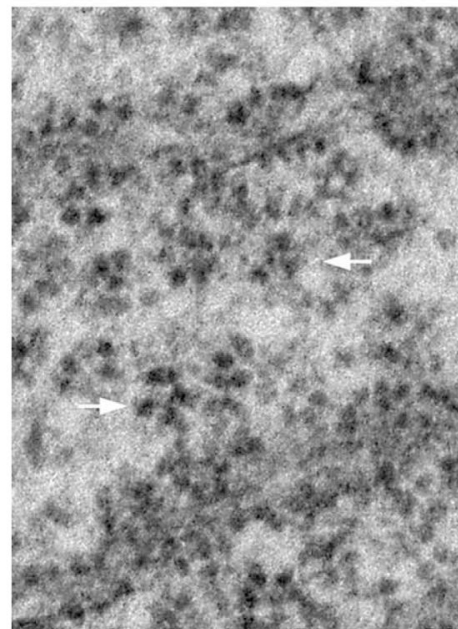

Sham

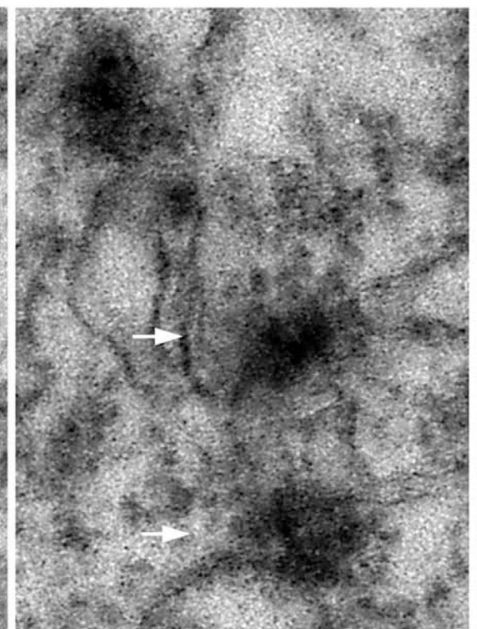

$4 \mathrm{~h}$

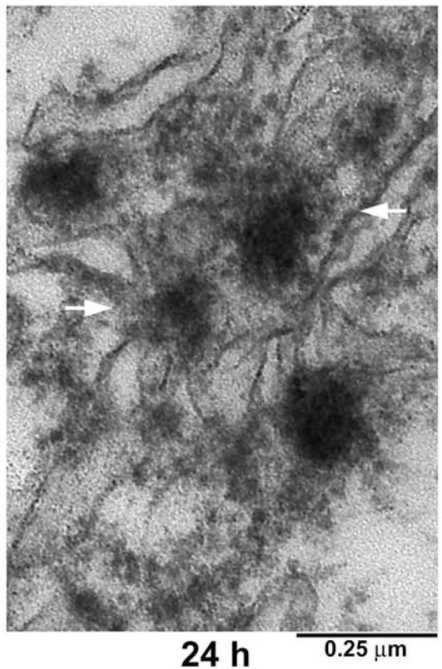

$24 \mathrm{~h}$

Fig. 2.

Electron micrographs of CA1 neurons from a sham-operated control rat and rats subjected to $15 \mathrm{~min}$ of ischemia followed by 4 and $24 \mathrm{~h}$ of reperfusion. CA1 sections were stained with the osmium- uranyl-lead method. Upper panel: The ER, M, N, G and ribosomal rosettes (arrows) were normally distributed in a CA1 neuron from a sham-operated brain (Sham, upper panel). After ischemia, ribosomes were clumped into large aggregates at 4 and $24 \mathrm{~h}$ of reperfusion (24 h, upper panel, arrows). In addition, many intracellular vacuole (V), probably derived from disassembled $\mathrm{G}$, was increased during the postischemic phase. Lower panel: Higher magnification of the ribosomal ultrastructures indicated by arrows in the upper panel. Ribosomal rosettes were distributed normally in CA1 neurons from shamoperated control (Sham, lower panel, arrows). After ischemia, ribosomes were abnormally clumped into large aggregates at 4 and $24 \mathrm{~h}$ of reperfusion $(4 \mathrm{~h}$ and $24 \mathrm{~h}$, lower panel, arrows). The results are highly reproducible from at least four rats in each experimental group. 

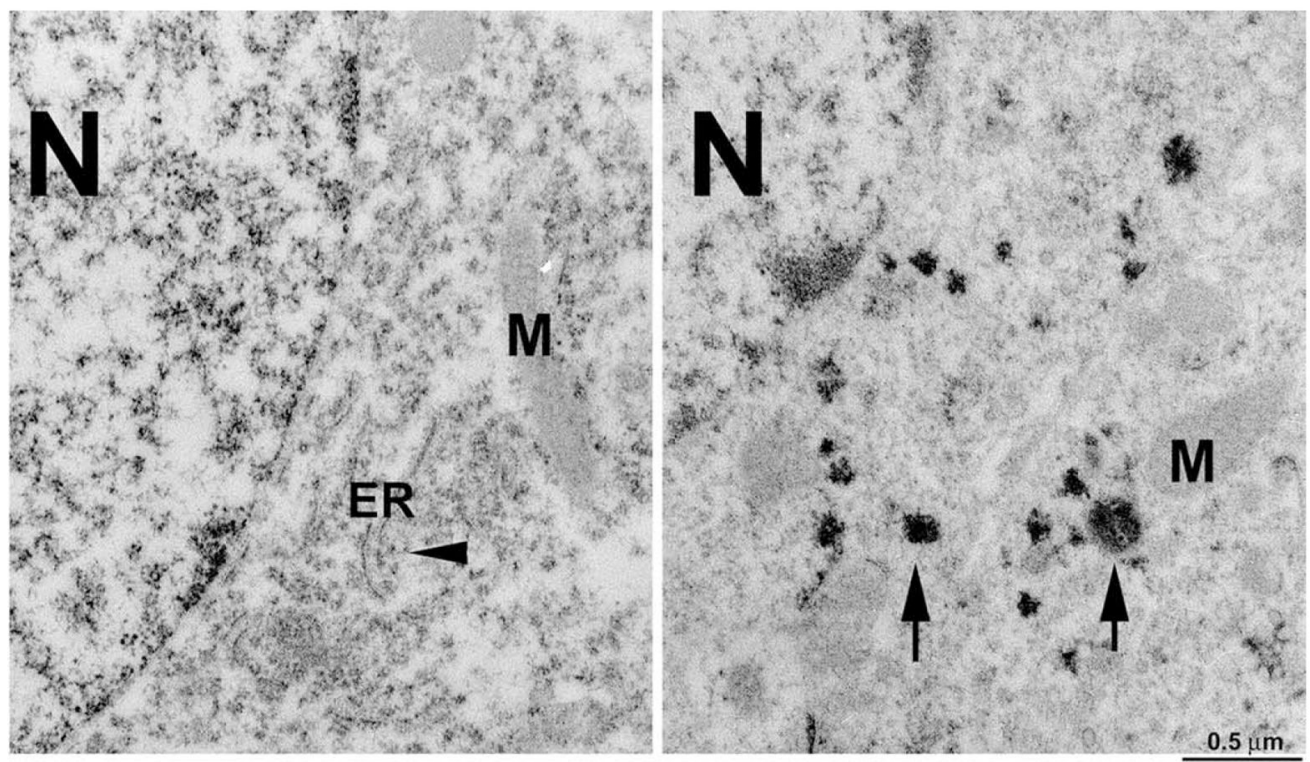

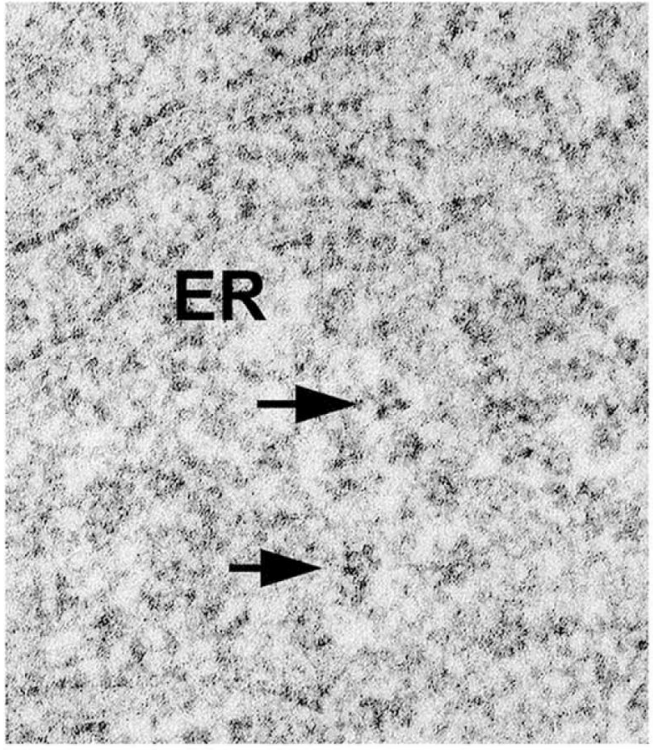

Sham

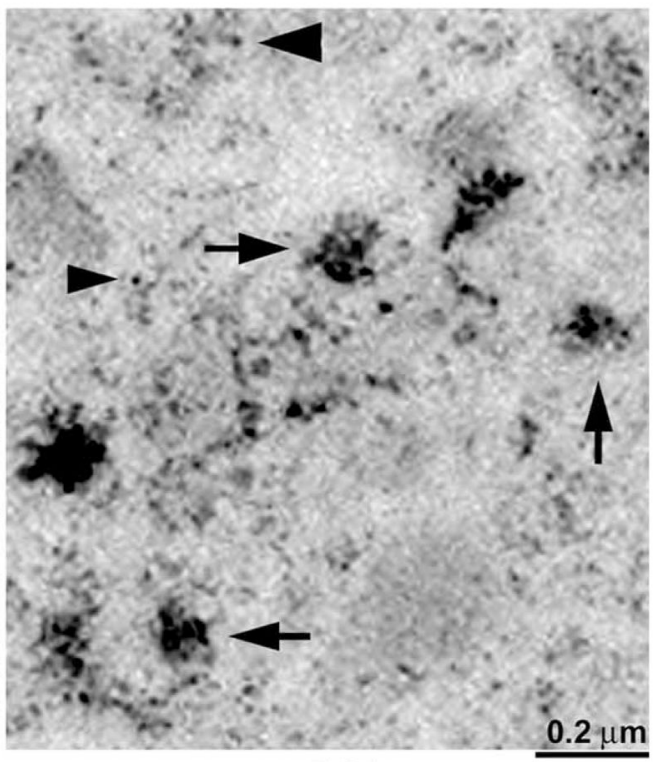

$24 \mathrm{~h}$

Fig. 3.

Electron micrographs of CA1 neurons from a sham-operated control rat and a rat subjected to $15 \mathrm{~min}$ of ischemia followed by 4 and $24 \mathrm{~h}$ of reperfusion. The sections were stained with EPTA before embedding and further stained with a ribosomal-selective staining method after embedding. The ER and $M$ were often visible in negative contrast. Upper panel: The $\mathrm{ER}, \mathrm{M}, \mathrm{N}$, and ribosomal rosettes were normally distributed in a CA1 pyramidal neuron from a sham-operated control (Sham, upper panel, arrowhead). After ischemia, scattered ribosomes were clumped into large aggregates ( $24 \mathrm{~h}$, upper panel, arrows). Lower panel: Higher magnification of ribosomal ultrastructures in CA1 neurons. Ribosomal rosettes and the ER-associated ribosomal studs were distributed normally in a CA1 neuron from a shamoperated control rat (Sham, lower panel, arrows). After ischemia, ribosomes were abnormally clumped into large aggregates ( $24 \mathrm{~h}$, lower panel, arrows) and a few single 
ribosomes were seen in the cytoplasm ( $24 \mathrm{~h}$, lower panel, arrowheads). The results are reproducible in at least four rats in each experimental group. 

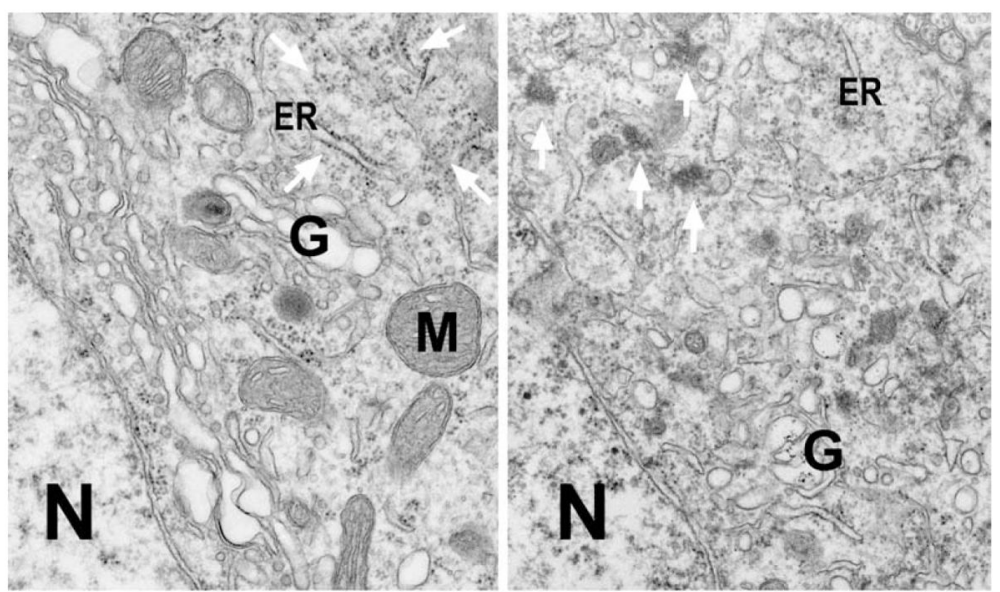

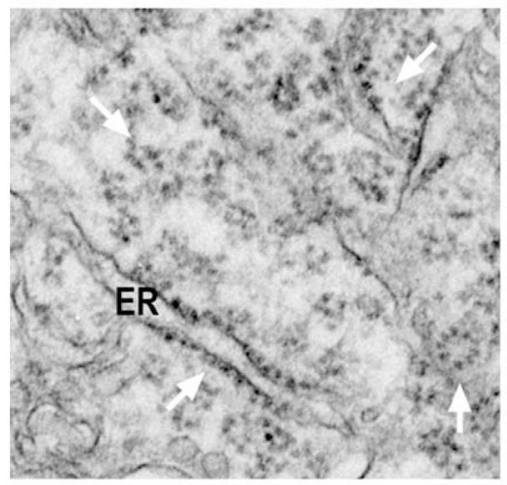

Sham Cx

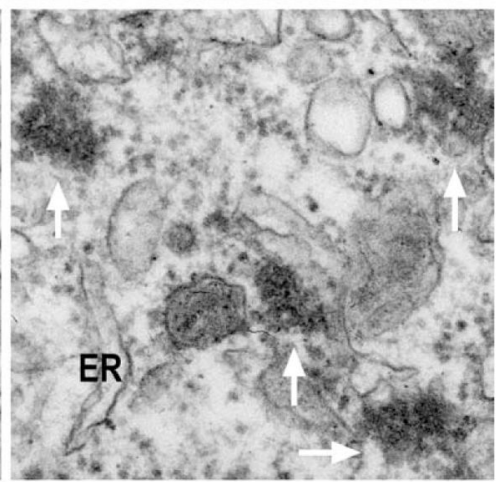

24 h Cx

Fig. 4.

Electron micrographs of neocortical neurons from a sham-operated control rat and a rat subjected to $20 \mathrm{~min}$ of ischemia followed by $24 \mathrm{~h}$ of reperfusion. Sections from dorsolateral neocortical regions were stained with the osmium- uranyl-lead method. Upper panel: The $\mathrm{ER}, \mathrm{M}, \mathrm{N}, \mathrm{G}$ and ribosomal rosettes (arrows) were normally distributed in a neocortical neuron from a sham-operated brain (Sham Cx, upper panel). After ischemia, ribosomes were clumped into large aggregates in a postischemic neocortical neuron at $24 \mathrm{~h}$ of reperfusion ( $24 \mathrm{~h} \mathrm{Cx}$, upper panel, arrows). In addition, the $\mathrm{G}$ was disassembled during the postischemic phase. Lower panel: Higher magnification of the ribosomal ultrastructures indicated by arrows in the upper panel. Ribosomal rosettes were distributed normally in neocortical neurons from sham-operated control (Sham Cx, lower panel, arrows). After ischemia, ribosomes were abnormally clumped into large aggregates at $24 \mathrm{~h}$ of reperfusion $(24 \mathrm{~h} \mathrm{Cx}$, lower panel, arrows). The results are reproducible from at least four rats in each experimental group. 

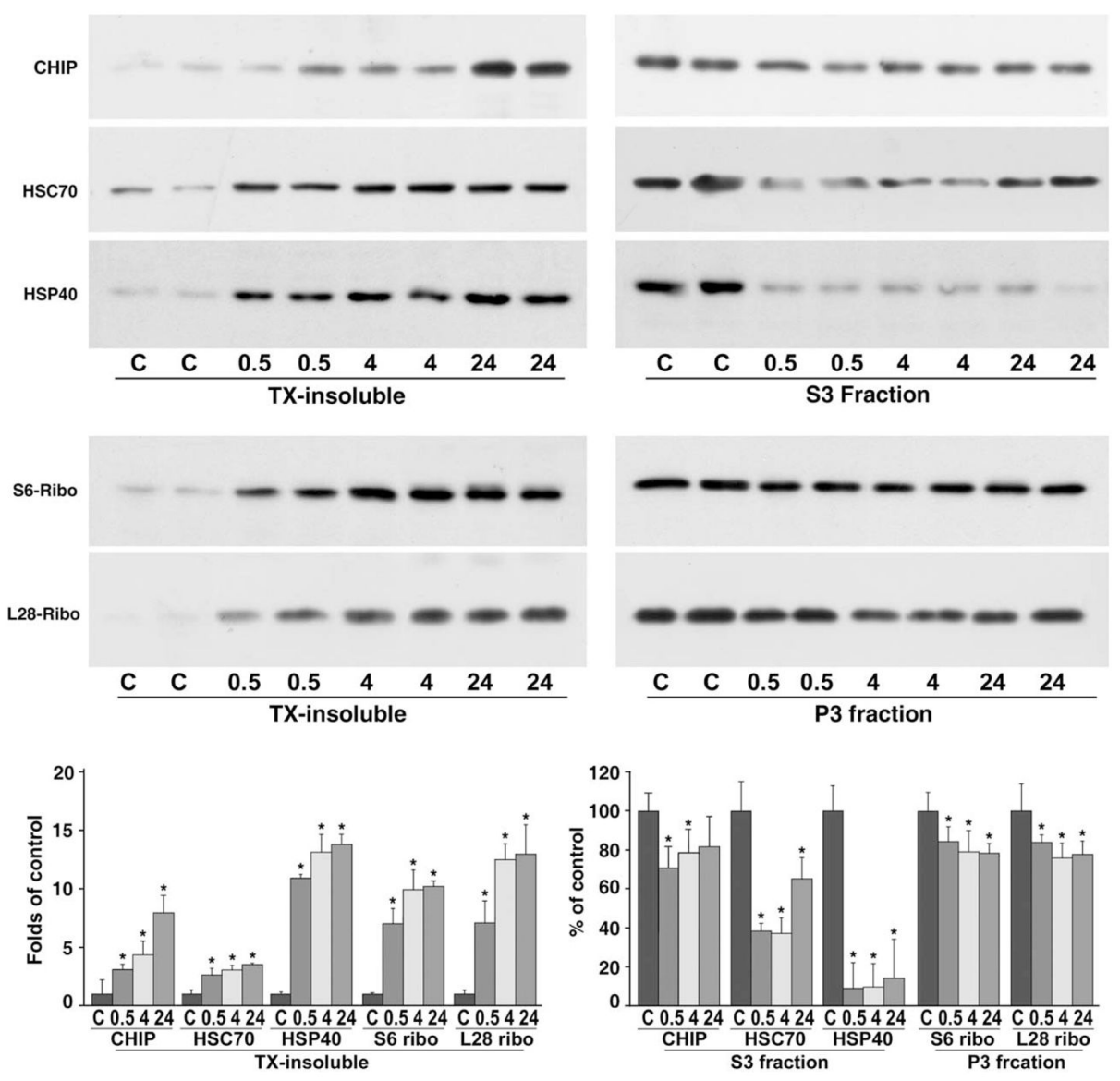

Fig. 5.

Immunoblots of CHIP, HSC70, Hdj1, ribosomal S6 protein and L28 protein in detergent/ salt-insoluble protein aggregate-containing fraction (left panels), and in either cytosolic S3 fraction or microsomal P3 fraction (right panels) from the dorsolateral neocortical tissues after brain ischemia. Samples were prepared from sham-operated control rats (C) and rats subjected to $20 \mathrm{~min}$ of cerebral ischemia followed by $0.5,4$ and $24 \mathrm{~h}$ of reperfusion. Each sample was derived from one rat. Two separate samples in each experimental group were run on the same SDS-PAGE. Upper immunoblotting panels: The blots were labeled with antibodies against CHIP, HSC70, Hdj1, S6 and L28, and visualized with the ECL system (upper immunoblot panels). Lower panel: Changes in protein bands of CHIP, HSC70, Hdj1, S6 and L28 from four different individual rat samples were evaluated with Kodak 1D image software. Data are expressed as mean \pm S.D. $(n=4)$. * Denotes $P<0.05$ between control and experimental conditions, one-way ANOVA followed by Fisher's PLSD post hoc test. 


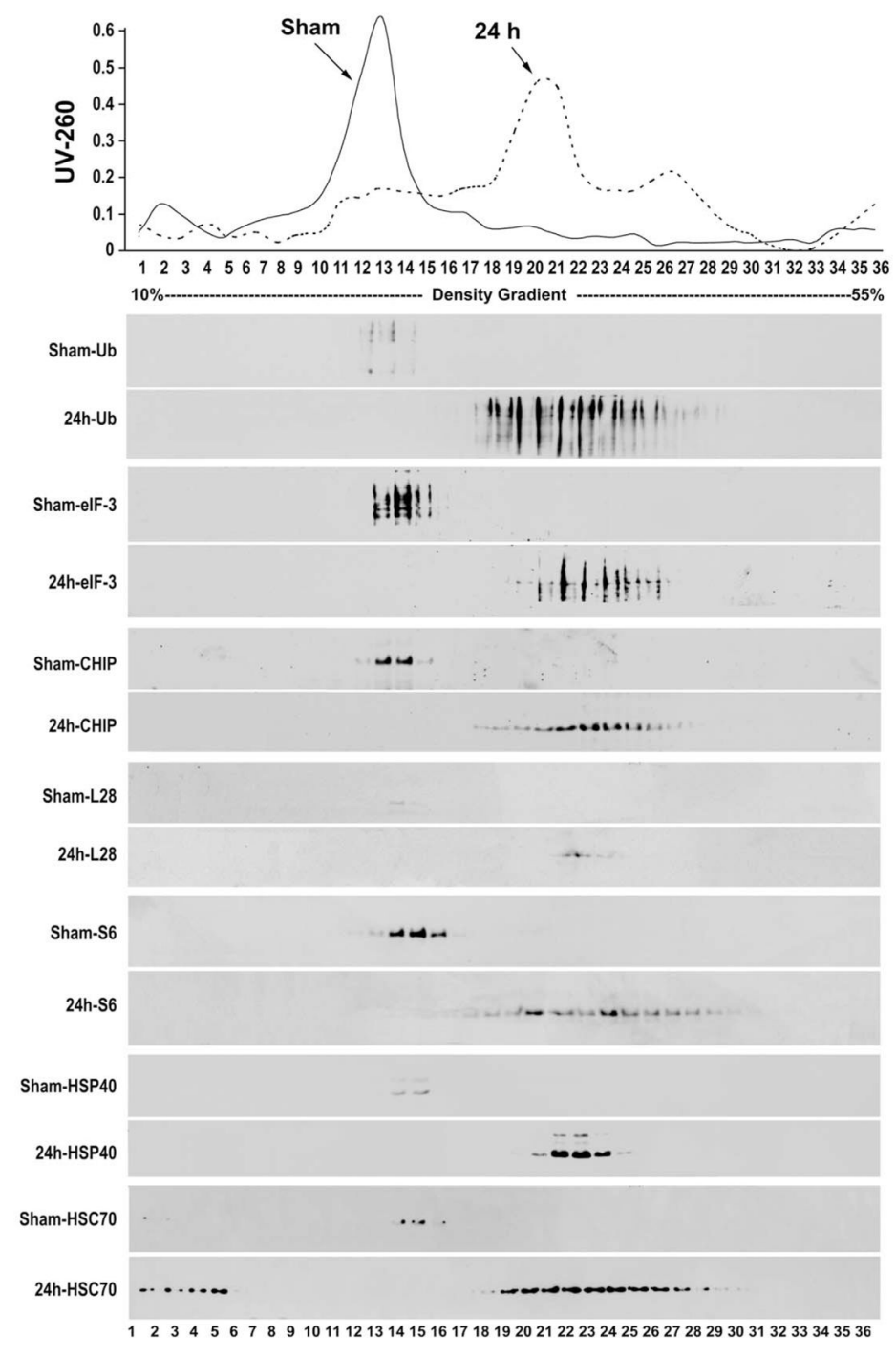

Fig. 6.

Sedimentation profile analysis of the detergent-insoluble fraction in sucrose density gradient (the top panel) and Western blot analysis of translational components (lower 14 immunoblotting panels) in the dorsolateral neocortical tissues after brain ischemia. Rats were subjected to either sham surgery or $20 \mathrm{~min}$ of ischemia followed by $24 \mathrm{~h}$ of reperfusion. The 1\% TX100/400 mM KCl detergent/salt-insoluble fractions were resolved in $10-55 \%$ sucrose gradients by ultracentrifugation, and the sedimentation profiles were recorded by the UV absorbance at $260 \mathrm{~nm}$ (the top panel). Top panel: One major UV260 nm absorbance peak at density fractions 11-14 corresponding to 80S ribosome from shamcontrol sample was resolved in the density gradient (sham arrow, solid line). This peak was shifted to higher density fractions $18-21$ in the postischemic sample ( $24 \mathrm{~h}$ arrow, dashed line). Lower Immunoblotting panels: High-molecular weight ubi-proteins (ub), as well as eIF-3ך, CHIP, L28, S6, Hdj1 and HSC70 were resolved in the ribosomal peak in shamoperated control samples (sham-immunoblot panels). Relative to those in control samples, much larger quantities of these translational complex components were resolved in higher sucrose densities in postischemic samples (24 h-immunoblot panels). The results were reproducible in four different samples prepared from four different rats in each experimental group. 